\title{
Trichostrongylus colubriformis
}

National Cancer Institute

\section{Source}

National Cancer Institute. Trichostrongylus colubriformis. NCI Thesaurus. Code C125969.

A species of parasitic roundworms in the family Trichostrongylidae that causes black scour disease in sheep, cattle, and goats. 